\title{
ADOLESCENTS' PHYSICAL SELF-PERCEPTION AS RELATED TO MODERATE-TO-VIGOROUS PHYSICAL ACTIVITY: A ONE-YEAR LONGITUDINAL STUDY
}

\author{
R. Viira \\ Institute of Sport Pedagogy and Coaching, University of Tartu, Estonia
}

\begin{abstract}
The aim of the present longitudinal study was to follow the development of self-perceptions during early adolescence. The final samples for this study were 203 adolescents (105 girls, and 98 boys; mean age $=15.2, \mathrm{SD}=0.57)$. Adolescents completed Children's Physical SelfPerception Profile the four subdomain scales (sport competence, physical conditioning, strength, and body attractiveness), the general domain scale of physical self-worth, a global scale of self-worth. Longitudinal research indicates that the boys' perceptions of condition, sport, body, strength, physical self-worth and global self-worth were higher and they participated more in moderate to vigorous physical activity compared to girls. Sport and physical self-worth domains were the strongest predictors of moderate to vigorous physical activity for boys. Body and condition domains emerged as important predictors for girls. Our results demonstrate that physical selfperceptions are significant subdomains to physical activity and very stable at a moderate level during early adolescence.
\end{abstract}

Key words: gender differences, sport competence, physical conditioning, strength, body attractiveness, physical and global self-worth. 


\section{INTRODUCTION}

Physical activity has been shown to assist children's psychological well-being and may assist their adherence to regular physical activity participation into adulthood [18]. There has been an increased interest in determining the influence of specific physical self-perceptions on health-related behavior in children and adolescents [7, 4, 14]. Whitehead [21] found that physical self-perceptions of body, sport competence, physical conditioning and general physical self-worth were all related to several field indicators of anaerobic, aerobic and muscular strength in seventh- and eighth-grade students. In general, a belief in one's ability greatest expectation of success, which in turn directs choice and persistence in behavior. Given the opportunity, those behaviors are sought that provide a sense of competence, and those avoided that carry a high probability of failure.

Studies among adolescents [17] have demonstrated an association between perceived athletic competence and involvement in sports. Research has shown that self-perceptions are most negative in early adolescence, girls have been shown to have lower self-esteem and a more dramatic decline through this period compared to boys [23]. Trzesniewski et al. [20], for example, found that interventions should target early adolescence because self-esteem stability at that developmental period is relatively low. In addition, Harter [11] indicated that physical self-perception was found to be the single most important predictor of general self-esteem across ages, especially in females. Great psychological and physiological changes take place in early adolescence, which probably affect the level of self-perceptions. Hagger et al. [8] investigated cross-cultural and sex differences in predicting moderate physical activity from self-perception. They found that several subdomains of physical self-perceptions (physical conditioning, sport competence, physical strength) were able to distinguish between highactive and low-active Russian and British children.

Reviewed several longitudinal studies the data showed self-esteem to increase in self-esteem with age [2]. Other longitudinal studies evaluating the stability of physical self-perceptions [1, 4, 15]. Raudsepp et al. [15] results indicated relatively high stability of the subdomains of physical self-perceptions at a group level, although instability of these self-perceptions at an individual level was observed. Therefore, the present longitudinal study adds a unique point of view to research on adolescents in Estonia. 
The aim of this study was to examine the relationship between physical self-perceptions and moderate-to-vigorous physical activity in adolescents in the longitudinal study.

\section{METHODS}

\section{Participants and procedures}

The final sample for this study were 203 adolescents (105 girls, mean age $=15.3, \mathrm{SD}=0.61$; and 98 boys, mean age $=15.1, \mathrm{SD}=0.53$ ) from three schools from a town of 100,000 inhabitants located in southeast of Estonia. The present study included two data collections over the course of 12 months. The first time participants were in grade eighth. Two hundred and sixty-eight students took part in the first data collection (Time 1). An attrition rate of $24.3 \%$ at Time 2 was primarily due to students being absent from the schools on the day of the data collection. Using dummy-coding (stay vs. dropout) to test for possible differences among those students who took part in the second data collection (Time 2) and those who did not, the independent samples $t$-test was conducted on the mean scores of each study variable. No significant differences emerged on the variables, suggesting that attrition did not affect the results reported in this study.

\section{Measures}

All original inventories were translated into Estonian. After making some revisions in the translated versions, the items were then back translated into English by a bilingual expert. The factorial validity of the Children's Physical Self-Perception Profile (CY-PSPP) was tested with Confirmatory Factor Analysis using LISREL 8 [12]. The 36-item measurement model (i.e., six indicators per factor) provides an satisfactory fit to the translated CY-PSPP data $\left(\chi^{2}(579)=2416.18\right.$, $\mathrm{p}=0.001$, RMSEA $=0.042 ; \mathrm{NNFI}=0.92 ; \mathrm{CFI}=0.94 ; \mathrm{IFI}=0.93) . \quad \mathrm{CY}-$ PSPP internal reliability using Cronbach's alpha coefficients for subdomains are presented in Table 1-2.

\section{Perceived Competence}

Perceived competence was assessed using the CY-PSPP [21]. The CY-PSPP consists of four subdomains that assess perceptions of sports competence (SPORT), physical condition (CONDITION), body 
attractiveness (BODY), and strength (STRENGTH). Three of the four subdomains (CONDITION, BODY, and STRENGTH) were based on modifications of Fox's original Physical Self-Perception Profile (PSPP) scales [6]. Harter's sport/athletic competence scale [9] was used for the SPORT scale since it was conceptually similar to Fox's original sport scale [6] and had been previously validated with children. A fifth subscale assessing global physical self-worth scale (PSW) [22] and sixth subscale general self-worth scale (GSW) [9] were included in the profile. Each scale contained six items in a structured alternative format [21]. The subjects first determined which of two options was most characteristic of him or her and then decided whether it was really true or only somewhat true of him or her. This format has been shown to reduce the tendency toward socially desirable responses [10]. The values ranged from 1 to 4 , with the midpoint of the scale occurring at 2.5.

\section{Physical activity}

The physical activity assessment was accomplished using self-report of activity level on a series of 19 activity items [16], with three spaces for "other" activities. The scale was created to obtain an aggregate measure of the physical activity engaged in a weekly basis. Each level of the scale was assigned a weight as follows: $1 / 2$ for " $1-3$ times a month," 2 for "1-2 times a week," 4 for "3-5 times a week," 6 for "Almost every day," and 7 for "Every day." Participants reported the level at witch they participated in each activity on a scale ranging from 1 "Never" to 7 "Every Day." Students were instructed to circle the number on the scale that corresponded to how often they participated in each activity for a least 20 min nonstop. For example, if a student never played volleyball they would circle " 1 " representing "Never" and if they played basketball twice a week they would circle " 4 " representing " $1-2$ times a week." These were used to estimate the number of times the subject engaged in each activity each week. These weights were then summed across the 19 (or more) activities to reach a total activity score. Evidence for the validity of the measure was found in the Stanford Adolescents Heart Health Program (SAHHP) [13] where self-reported regular exercisers were found to have resting heart rates lower than those of non-regular exercisers. 


\section{Statistical Analysis}

The data analysis involves descriptive statistics, test-retest reliability, Coefficient $\alpha$ and multivariate analysis of relationships with MVPA. Dependent $t$ test was performed to reveal differences in selfperception and MVPA measures. A longitudinal regression analysis was used to predict the variance in MVPA. Statistical significance was set at $\mathrm{p}<0.05$.

\section{RESULTS}

\section{Descriptive Statistics and Scale Reliabilities}

Descriptive statistics, Coefficient $\alpha$ and Test-retest reliability for all variables are show in Tables 1 and 2. Physical activities were determined for MVPA scores across genders and CY-PSPP variables at the first measurement and at the second measurement with the some subjects were compared to assess changes that may have occurred.

\section{Differences between first and at the second measurement}

Dependent $t$ test comparisons were conducted separately for boys and girls on the independent variables to assess changes that may have occurred. Results showed (Table 1) that for boys, statistically significant difference was significantly higher level of SPORT $t(1,101)=$ $7.45, \mathrm{p}<0.001$. Girls (Table 2) reported no differences between first and second measurement.

Table 1. Means, Standard Deviations, test-retest reliability and Coefficient $\alpha$ for the CY-PSPP items and physical activity for boys.

\begin{tabular}{|c|c|c|c|c|c|c|}
\hline \multirow{3}{*}{ Age } & \multirow{3}{*}{ Alpha } & \multicolumn{4}{|c|}{ Boys $(n=98)$} & \multirow{3}{*}{ test-retest } \\
\hline & & \multicolumn{2}{|c|}{14} & \multicolumn{2}{|c|}{15} & \\
\hline & & mean & SD & mean & SD & \\
\hline MVPA (points) & & 11.28 & 3.1 & 11.43 & 4.7 & 0.93 \\
\hline SPORT & 0.758 & 2.71 & 0.68 & $3.06^{*}$ & 0.65 & 0.81 \\
\hline CONDITION & 0.783 & 2.99 & 0.73 & 3.04 & 0.74 & 0.79 \\
\hline STRENGHT & 0.818 & 2.69 & 0.62 & 2.72 & 0.67 & 0.87 \\
\hline BODY & 0.723 & 2.74 & 0.76 & 2.84 & 0.78 & 0.92 \\
\hline PSW & 0.713 & 2.79 & 0.74 & 2.91 & 0.62 & 0.85 \\
\hline GSW & 0.765 & 2.93 & 0.65 & 3.07 & 0.65 & 0.93 \\
\hline
\end{tabular}

MVPA - moderate to vigorous physical activity; PSW - physical selfworth; GSW - general self-worth. *p $<0.05$ 
Table 2. Means, Standard Deviations, test-retest reliability and Coefficient $\alpha$ for the CY-PSPP items and physical activity for girls.

\begin{tabular}{|c|c|c|c|c|c|c|}
\hline \multirow{3}{*}{ Age } & \multirow{3}{*}{ Alpha } & \multicolumn{4}{|c|}{ Girls $(n=105)$} & \multirow{3}{*}{ test-retest } \\
\hline & & \multicolumn{2}{|c|}{14} & \multicolumn{2}{|c|}{15} & \\
\hline & & mean & SD & mean & SD & \\
\hline MVPA (points) & & 10.35 & 8.1 & 10.56 & 6.7 & 0.87 \\
\hline SPORT & 0.884 & 2.68 & 0.76 & 2.76 & 0.70 & 0.85 \\
\hline CONDITION & 0.703 & 2.72 & 0.74 & 2.82 & 0.69 & 0.78 \\
\hline STRENGHT & 0.722 & 2.46 & 0.69 & 2.54 & 0.60 & 0.87 \\
\hline BODY & 0.663 & 2.58 & 0.73 & 2.51 & 0.66 & 0.92 \\
\hline PSW & 0.673 & 2.91 & 0.75 & 2.97 & 0.64 & 0.95 \\
\hline GSW & 0.725 & 2.89 & 0.63 & 2.93 & 0.75 & 0.86 \\
\hline
\end{tabular}

MVPA - moderate to vigorous physical activity; PSW - physical selfworth; GSW - general self-worth.

\section{Longitudinal regression model - Boys}

Longitudinal regression analyses were conducted in order to determine the extent to which adolescent's exercise could be predicted from CY-PSPP subdomains gathered at the second measurement. Level of physical activity at the first measurement was statistically controlled by forcing it into each model first. Two variables entered the equation. SPORT emerged as a determinant of physical activity, $\mathrm{F}(2,99)=6.72, \mathrm{p}<0.001$, accounted for $20 \%$ of the variance. PSW accounted for $12 \%$ of the variance, $F(2,99)=5.85, p<0.001$. Together these variables accounted for $32 \%$ of the variance in the criterion.

\section{Longitudinal regression model - Girls}

Two variables entered the equation. BODY accounted for $16 \%$ of the variance, $F(2,95)=3.85, p<0.05$. CONDITION accounted for $14 \%$ of the variance, $F(2,95)=3.73, \mathrm{p}<0.05$. Together these variables accounted for $30 \%$ of the variance in the criterion.

\section{DISCUSSION}

The aim of the longitudinal study was to examine the relationship between physical self-perceptions and MVPA in grades eighth to ninth. This analysis was conducted to provide a better understanding of children's perceptions of motor competence. 
Our results showed that boys reported statistically higher levels of SPORT. Being physically competent is clearly socially desirable for boys; therefore, they may have had a strong tendency to overrate themselves. Girls reported no differences between first and the second measurement. Girls are not rewarded for overstating perceptions: boasting is unfeminine. On the basis of the previous research in both academic and physical domains $[1,5,9,15,20]$, it was hypothesized that accuracy in competence judgments would increase with the progression of the early adolescence.

An interesting finding was that the changes were minor among the boys and the girls. The reason for the stability and small changes in the mean levels of self-perceptions observed during adolescence may lie partly in the defense of the conscious self-concept against threatening or inconsistent information by means of various mechanisms $[1,4]$. The results indicated, however, that SPORT and CONDITION domains were the strongest predictors of adolescent males and females MVPA involvement. SPORT is likely to be influential in adolescents' MVPA because of widespread involvement in organized sport both of schools and outside sport club organizations. Many of these most frequent physical activities also require a significant aerobic fitness of conditioning component. SPORT domain is likely to be influential in children's exercise participation because of widespread involvement in organized sport in both elementary school system and outside sport club organizations [3]. Using structural equation modeling techniques, physical self-perception models were able to predict $20-29 \%$ of the variance of the physical activity scores in both boys and girls. The variance explained by these models represents acceptable effect sizes when compared with values reported for psychosocial correlates of activity [19]. Furthermore, there was no evidence that sex moderated the relationship between physical self-perceptions and physical activity.

In this study, these adolescents had positive self-esteem during the follow-up period. The longitudinal analyses suggested that for boys' physical activity at the earlier age was strongly correlated with physical activity level during the eighth- and ninth-grade years $(\mathrm{r}=0.31)$. Important predictors of later physical activity for boys were CONDITION and PSW. For girls, previous level of physical activity was not correlated with physical activity at the second measurement $(\mathrm{r}=0.15)$. Other variable to enter the regression equation were BODY and CONDITION. Previous longitudinal research (mainly regarding 
self-esteem) has shown the correlations between two time-points to be high, thus indicating high stability during adolescence $[1,15]$ and also have concluded that self-esteem is likely to become more fixed or more consolidated with increasing age.

In summary, the major findings of this longitudinal study were that (a) CY-PSPP subdomains are important determinants of physical activity among early adolescents (b) boys' perceptions of CONDITION, SPORT, BODY, STRENGTH, PSW and GSW were higher and they participated more in MVPA compared to girls (c) longitudinal component of this study illustrates that the relative importance of determinants were very stable.

\section{REFERENCES}

1. Amorose A. (2001) Intraindividual variability of self-evaluations in the physical domain: Prevalence, consequences, and antecedents. J. Sport Exerc. Psychol. 23: 222-244

2. Butcher J. (1989) Adolescent girl's sex role development: Relationships between sport participation, self-esteem, and age at menarche. Sex Roles. 20: 575-593

3. Crocker P. R. E., Eklund R. C., Kowalski K. C. (2000). Children's physical activity and self-percpetion. J. Sport Sci. 18: 383-394

4. Crocker P. R. E., Sabiston C. M., Kowalski K. C., McDonough M. H., Kowalski N. (2006) Longitudinal assessment of the relationship between physical self-concept and health-related behavior and emotion in adolescent girls. J. Appl. Sport Psychol. 18: 185-200

5. Donnelan M. B., Trzesniewski K. H., Conger K. J., Conger R. D. (2007) A three-wave longitudinal study of self-evaluations during adulthood. J. Res. Pers. 41: 453-472

6. Fox K. R. (1990) The Physical Self-Perceptions Profile Manual. DeKalb, IL: Northern Illinois University, Office for Health Promotion

7. Hagger M. S., Asci H. F., Lindwall M. (2004) A cross-cultural evaluation of a multidimensional and hierarchical model of physical self-perceptions in three national samples. J. Appl. Soc. Psychol. 34: 1075-1107

8. Hagger M., Ashford B., Stambulova N. (1998). Russian and British children's physical self-perceptions and physical activity participation. Pediatr. Exerc. Sci. 10: 137-152 
9. Harter S. (1982) The perceived competence scale for children. Child Dev. 53: 87-97

10. Harter S. (1985) Competence as a dimension of self-evaluation: Toward a comprehensive model of self-worth. In: The development of the self, R. Leahy (ed). New York: Academic Press. 55-121

11. Harter S. (1999) The construction of the self: A developmental perspective. New York: Guilford

12. Jöreskog K. G., Sörbom D. (1993) LISREL 8 user's reference guide. Chicago: Scientific Software International

13. Killen J. D., Telch M. J., Robinson T. N., Maccoby N., Taylor C. B., Farquhar J. W. (1998) Cardiovascular disease risk reduction in tenth grades: A multiple factor school-based approach. JAMA 260: 17281733

14. Lau P. W. C., Cheung M. W. L., Ransdell L. B. (2008) A structural equation model of the relationship between body perception and selfesteem: Global physical self- concept as themediator. Psychol. Sport Exerc. 9: 493-509

15. Raudsepp L., Kais K. Hannus A. (2004) Stability of physical selfperceptions during early adolescence. Pediatr. Exerc. Sci. 16: 138146

16. Reynolds K. D., Killen J. D., Bryson S. W., Maron D. J., Taylor C. B., Maccoby N., Farquhar J. W. (1990) Psychosocial Predictors of Physical-Activity in Adolescents. Prev. Med. 19: 541-551

17. Roberts G. C., Kleiber D. A., Duda J. L. (1981) An analysis of motivation in children's sport: The role of perceived competence in participation. J. Sport. Exerc. Psychol. 3: 206-216

18. Shephard R. J. (1995) Physical activity, health, and well-being at different life stages. Res. Q. Exerc. Sport. 66: 298-302

19. Taylor W. C., Sallis J. F. (1997) Determinants of physical activity in children. In: Nutrition and fitness: Metabolic and behavioral aspects in health and disease, A. P. Simopolous, K. N. Pavlou (Eds). Basel, Switzerland: Karger. 82: 159-167

20. Trzesniewski K. H., Donnellan M. B., Robins R. W. (2003) Stability of self-esteem across the life-span. J. Pers. Soc. Psychol. 84: 205-220

21. Whitehead J. R. (1995) A study of children's physical self-perceptions using an adapted physical self-perception profile questionnaire. Pediatr. Exerc. Sci. 7: 132-151

22. Whitehead J. R., Corbin C. B. (1997) Self-esteem in children and youth: The role of sport and physical education. In The physical self: From motivation to well-being, K. R. Fox (Ed). Champaign, IL: Human Kinetics. 175-204 
23. Zimmerman A., Copeland L. A., Shope J. T., Dielman T. E. (1997) A longitudinal study of self-esteem: Implications for adolescent development. J. Youth Adolesc. 26: 117-142

\section{Correspondence to:}

Roomet Viira

Faculty of Exercise and Sport Sciences

University of Tartu

5 Jakobi Street

51014 Tartu

Estonia

email: roomet.viira@ut.ee 